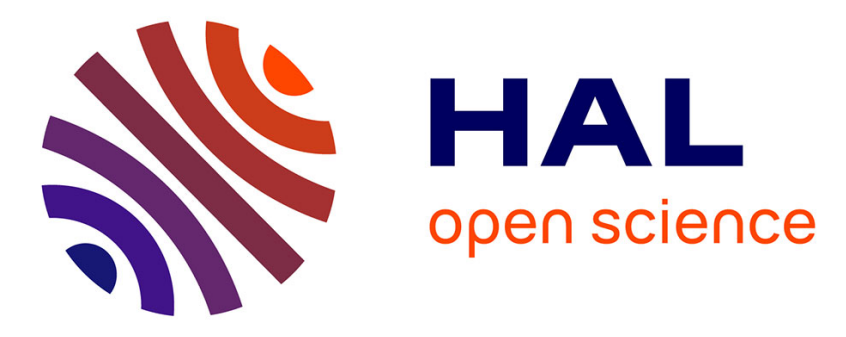

\title{
Sub-100nm Surface Self-organization By Ultrafast Laser Irradiation
}

\author{
Jean-Philippe Colombier, A Rudenko, A Nakhoul, A Abou-Saleh, C Maurice, \\ F Pigeon, F Garrelie
}

\section{- To cite this version:}

Jean-Philippe Colombier, A Rudenko, A Nakhoul, A Abou-Saleh, C Maurice, et al.. Sub-100nm Surface Self-organization By Ultrafast Laser Irradiation. CLEO US - Laser Sciences to Photonic Applications, May 2021, San Jose, United States. ujm-03230424

\section{HAL Id: ujm-03230424}

\section{https://hal-ujm.archives-ouvertes.fr/ujm-03230424}

Submitted on 19 May 2021

HAL is a multi-disciplinary open access archive for the deposit and dissemination of scientific research documents, whether they are published or not. The documents may come from teaching and research institutions in France or abroad, or from public or private research centers.
L'archive ouverte pluridisciplinaire HAL, est destinée au dépôt et à la diffusion de documents scientifiques de niveau recherche, publiés ou non, émanant des établissements d'enseignement et de recherche français ou étrangers, des laboratoires publics ou privés. 


\title{
Sub-100nm Surface Self-organization By Ultrafast Laser Irradiation
}

\author{
J.P. Colombier, ${ }^{1}$ A. Rudenko, ${ }^{1}$ A. Nakhoul,${ }^{1,2}$ A. Abou-Saleh, ${ }^{1}$ C. Maurice,${ }^{2}$ F. Pigeon,${ }^{1}$ F. Garrelie ${ }^{1}$ \\ 1 Univ Lyon, UJM-St-Etienne, CNRS, Institute of Optics Graduate School, Laboratoire Hubert Curien UMR 5516, \\ F-42023 Saint-Etienne, France \\ 2 Ecole Nationale Supérieure des Mines de Saint-Etienne, Laboratoire Georges Friedel, CNRS, UMR5307, 42023 St-Etienne, France \\ Author e-mail address: jean.philippe.colombier@univ-st-etienne.fr
}

\begin{abstract}
Driven by local field enhancements enhancing feedback, novel structuring features demonstrate the potential of ultrafast laser for the fabrication of self-organized patterns with a periodic topography well below the diffraction limit. We report the achievement of laser-induced nanocavities that results from the control of a Marangoni convection instability at the nanoscale.
\end{abstract}

\section{Experimental achievements}

Ultrafast laser-induced irradiation concentrates the light and the delivered energy on extreme spatial and temporal dimensions [1]. The absorbed energy is then confined to dimensions much smaller than the light wavelength $\lambda=800$ $\mathrm{nm}$ resulting in extreme thermo-mechanical conditions. In particular, when a femtosecond light beam interacts with the nanometric asperities of a surface, optical, thermal and mechanical effects can take place locally but also collectively. Upon multipulse irradiation, a dynamic self-organization established through a positive feedback process, forming patterns known as laser-induced periodic surface structures (LIPSS). Some of them reach periodicities down to one hundred of nanometers, and are commonly referred to as high-spatial frequency LIPSS. We have explored the inhomogeneous optical absorption mechanisms and the hydrothermal conditions that regulate their formation for ultrashort laser pulses. To take the structuring process and the analysis one step further, we propose a crossed-polarization strategy based on a Mach-Zehnder interferometer to produce fs-double pulse sequences. A regulation of the electromagnetic energy feedthrough combined with a loss of the polarization dependence was aimed [2]. At a low energy dose and by cross-polarized laser pulses delayed by $15-30 \mathrm{ps,} \mathrm{a} 2 \mathrm{D}$ nanostructuring has been obtained on nickel (100) samples as shown on Figure 1. The 2D hexagonal arrangement emerge upon multipulse irradiation of the double-pulse sequence owing to a precise polarization-dependence energy regulation. A scale factor of 10 has been gained compared to the literature for this kind of $2 \mathrm{D}$ patterns and we achieved highly uniform laser-induced array of nanocavities on the order of $20 \mathrm{~nm}$, self-organized in the microscale inside the laser spot $(50 \mu \mathrm{m})$ and with the possibility to be coherently repeated in the macroscale $(\mathrm{mm})$.

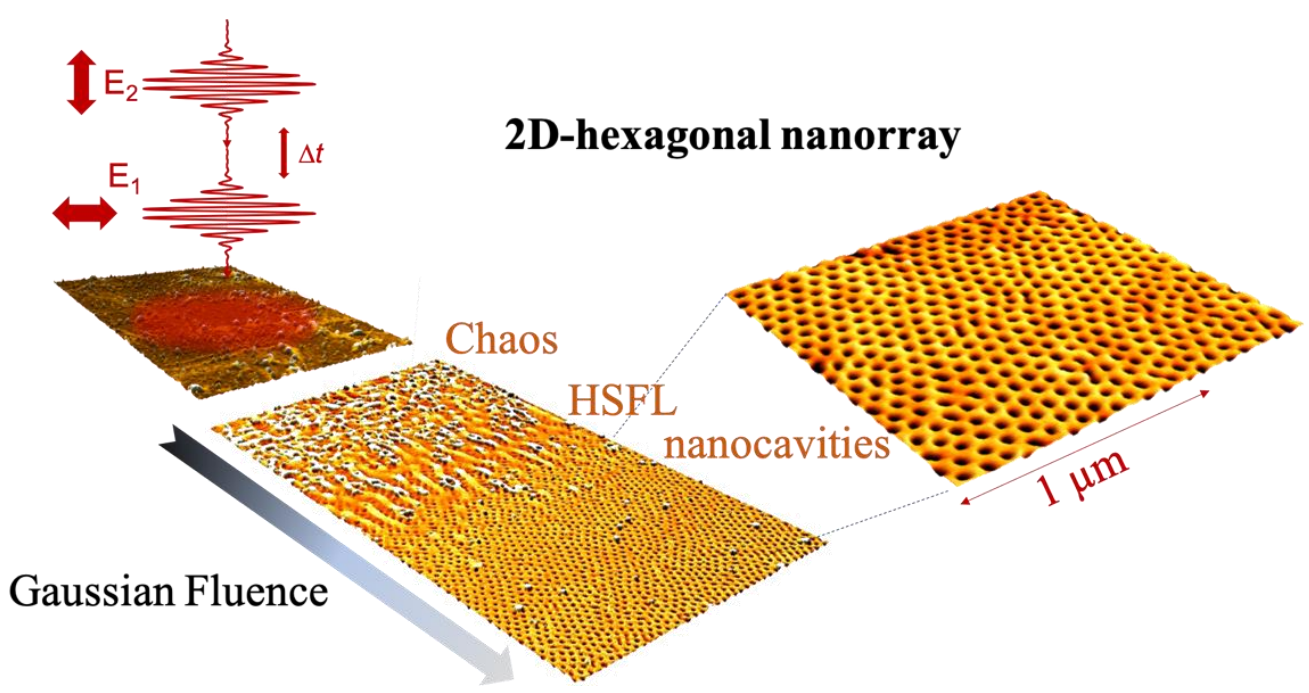

Figure 1: Crossed-polarized double pulse sequence for isotropic energy regulation. An hexagonal lattice of nanocavities of $20 \mathrm{~nm}$ in size and spaced by $60 \mathrm{~nm}$ has been performed on (100) Ni surface. 


\section{Theoretical investigations and simulation results}

The issue of laser-induced self-organization of the surface at the nanoscale, originating in near-field light-matter coupling, carries strong scientific weight as it puts forward the question on localizing light on extreme scales. Along with the experimental achievements, we have developed a model combining three-dimensional electromagnetic and hydrodynamic approaches to deliver a comprehensive frame for understanding light-induced structuring on tens of nanometer scales [3]. The numerical calculations allow us to investigate the multipulse evolution of surface relief in a self-consistent way, evaluating both the inhomogeneous absorption on surface roughness and the thermomechanical flows. Activated by transverse temperature gradients resulting from complex light coupling on the surface, we observed that the melt flow follows Marangoni surface tension forces. Destabilized by the associated rarefaction wave, we showed that a convection instability develops in thin laser-melted layers up to surface resolidification. This hydrodynamic instability, analog to the Rayleigh-Bénard one, drives the matter towards selforganized convection nanocells and, being sensitive to polarization dependence, can induce thermocapillary waves by transverse surface tension gradients. This results in periodic stripes with subwavelength spacings, corresponding to high-spatial frequency LIPSS formation and also to hexagonal convection cell patterns if the polarization dependence is intentionally erased. Coupling electromagnetism to hydrodynamics allow us to numerically replicate the different types of periodic structures commonly observed on metal surfaces, their precursors, origins of their periodicity and orientation, and plausible feedback mechanisms for their formation.

\section{Discussion}

The presented results deliver a comprehensive frame for the understanding of light-induced structuring on record scales as we elucidate that the generation of HSFL and hexagonal lattice result from the interplay between nonradiative optical response on surface and surface-tension driven flows, leading to the development of Marangoni convection instability. The optical and then thermoconvective response of a set of asperities now offers a unique process for manufacturing self-organized structures, porous or super-rough surfaces with a resolution of about ten nanometers. In addition to the fundamental interest, the one-step approach to fabricate nanocavities with periodicities down to one-tenth of laser wavelength offers a promising way to design and engineer surface properties in optics, plasmonics, sensing and mechanics, where hierarchical nanostructures can provide spectral-sensitive responses, local field-enhancement for nanosensing, or highly efficient catalytic activities. Patterning with ultrahigh resolutions plays also an increasing role in quantum physics, chemistry nano-sensing or energy physics as the resonance interaction between a molecular transition and a confined electromagnetic field can generate nonlinear energy exchanges.

\section{References}

[1] R. Stoian, \& J.P. Colombier, « Advances in ultrafast laser structuring of materials at the nanoscale », Nanophotonics 9 (16), $4665-4688$ (2020).

[2] A. Abou Saleh, A. Rudenko, S. Reynaud, F. Pigeon, F. Garrelie, \& J.P. Colombier, "Sub-100 nm 2D nanopatterning on large scale by ultrafast laser energy regulation", Nanoscale 12 (12), 6609 (2020).

[3] A. Rudenko, A. Abou-Saleh, F. Pigeon, C. Mauclair, F. Garrelie, R. Stoian, and J. P. Colombier "High-frequency periodic patterns driven by non-radiative fields coupled with Marangoni convection instabilities on laser-excited surfaces" Acta Materiala 194, 93 (2020). 